\title{
THE NOVEMBER MEETING IN MEXICO CITY
}

There was a joint meeting of the Sociedad Matemática Mexicana and the American Mathematical Society on Friday and Saturday, November 25-26, 1966, in Mexico City. It was the six hundred fortieth meeting of the Society. The sessions were at the Facultad de Ciencias at the National University of Mexico in Ciudad Universitaria.

At the Inaugural Session, Professor Guillermo Torres, VicePresident of the Sociedad Matemática Mexicana, addressed the audience on the nature and the felicity of the occasion. Ing. Javier Barros Sierra, Rector of the University, extended the welcome of the University and declared the session open.

There were two one-hour addresses by invited speakers. The American Mathematical Society invited Professor Richard K. Lashof of the University of Chicago, who spoke on Structures on manifolds. Professor Alberto Barajas presided and introduced the speaker. The Sociedad Matemática Mexicana chose Dr. José Adem of the Centro de Investigacion del Instituto Politecnico Nacional. $\mathrm{He}$ lectured on Immersion of projective spaces. Professor E. $\mathrm{H}$. Spanier presided and introduced the speaker.

There were eight sessions for about sixty contributed papers. The societies are grateful to Professors Humberto Cardenas, S. S. Feder, J. W. Green, Ismael Herrera, Carlos Imaz, Maurice L'Abbé, Emilio Lluis, and Murray Protter for presiding at these sessions.

The hosts provided delightful refreshment and the stimulus and opportunity for extended conversation in the interval between the morning and afternoon sessions on Friday.

At the closing session on Saturday, Professor J. W. Green of the University of California at Los Angeles presented the thanks of the participants to the hosts. Dr. Guillermo Massieu, Director of the Instituto Politecnico Nacional responded and declared the meeting closed.

The local arrangements were in the capable hands of Dr. Samuel Gitler of the Centro de Investigacion del I.P.N.

Everett Pitcher Associate Secretary

Bethlehem, Pennsylvania 